\title{
VIDA-DE-PRATELEIRA DE GOIABAS, CV. SASSAOKA, MINIMAMENTE PROCESSADAS E ARMAZENADAS EM DIFERENTES EMBALAGENS ${ }^{1}$
}

\author{
FLÁVIA APARECIDA DE CARVALHO MARIANO², APARECIDA CONCEIÇÃO BOLIANI ${ }^{3}$, \\ LUIZ DE SOUZA CORRÊA ${ }^{3}$, ERICA RODRIGUES MOREIRA ${ }^{2}$
}

RESUMO - O objetivo do trabalho foi estudar frutos de goiabeira da cultivar Sassaoka, submetidas ao processamento mínimo e armazenadas em dois tipos de embalagens por seis dias. O experimento foi conduzido no laboratório de Tecnologia de Alimentos, localizado na Universidade Estadual Paulista "Júlio de Mesquita Filho" (Unesp), Câmpus de Ilha Solteira - SP. Os frutos foram levados ao laboratório e posteriormente lavados, desinfectados, descascados, escorridos e acondicionados nas embalagens. Os tratamentos foram: embalagem PET e em bandeja de isopor com filme plástico $(14 \mu \mathrm{m})$, em quatro tempos. Os frutos foram armazenados durante seis dias, sob temperatura de $8^{\circ} \mathrm{C}$ e umidade relativa de $80 \%$. A cada dois dias de armazenamento refrigerado, foram retiradas três amostras de cada tratamento para as avaliações. Foram avaliados perda de massa, $\mathrm{pH}$, sólidos solúveis, acidez titulável, vitamina $\mathrm{C}$ e aparência visual. A embalagem de isopor (bandeja) com filme plástico proporcionou melhor conservação quando comparada com a embalagem PET, mantendo os frutos em boas condições por até quatro dias após processados. A embalagem PET apresentou tendência de acumular água dentro da embalagem, desde o segundo dia de armazenamento, sendo inadequada para essa finalidade. Os teores de vitamina $\mathrm{C}$ e sólidos solúveis foram maiores no final do armazenamento na embalagem PET, assim como o pH e a acidez titulável.

Termos para indexação: processamento mínimo, qualidade, Psidium guajava.

\section{SASSAOKA GUAVA MINIMALLY PROCESSED AND STORAGE}

\begin{abstract}
The objective of this work was to investigate the guava cv. Sassaoka, minimally processed and stored in two types of containers, for eight days. The experiment was conducted in the laboratory of Food Technology, Universidade Estadual Paulista "Julio de Mesquita Filho (Unesp), Campus de Ilha S - SP. Guava fruits cv. Sassaoka, were taken to the laboratory, processed and stored for 6 days at $8^{\circ} \mathrm{C}$ and relative humidity of $80 \%$. The treatments were: PET and polystyrene trays with plastic wrap $(14 \mu \mathrm{m})$ in four seasons. Every two days of storage three samples were taken from each treatment for evaluation of the loss of mass, the $\mathrm{pH}$, the soluble solids, the acidity, the vitamin $\mathrm{C}$ content and the visual appearance. The styrofoam packing (tray) with plastic wrap provided better preservation compared to the PET packaging, keeping the fruit in good condition for up to four days after processing. The PET has a tendency to accumulate water in the package, from the second day of storage, and was inadequate for this purpose. The vitamin $\mathrm{C}$ content and soluble solids were higher at the end of processing in PET packaging, as well as the $\mathrm{pH}$ and the acidity. Index terms: fruit processing, quality, Psidium guajava.
\end{abstract}

\footnotetext{
${ }^{1}$ Trabalho Sinfruit 142 - Simpósio Internacional de Fruticultura - Avanços na Fruticultura (17 a 21 Outubro)

${ }^{2}$ Engenheiro (a) Agrônomo (a), doutorando (a) em Agronomia/Sistemas de Produção, UNESP, Campus de Ilha Solteira, Av. Brasil 56, Ilha Solteira-SP, CEP15385-000. E-mail: flaviamariano1@hotmail.com; erica_rmoreira@hotmail.com

${ }^{3}$ Docentes do Departamento de Fitotecnia, Tecnologia de Alimentos e Socioeconomia/UNESP - Câmpus de Ilha Solteira, Av. Brasil 56, Ilha Solteira-SP, CEP 15385-000. E-mail: boliani@agr.feis.unesp.br, jacira@agr.feis.unesp.br, lcorrea@agr.feis.unesp.br
} 


\section{INTRODUÇ̃̃O}

O processamento mínimo de frutas é uma técnica em crescimento no mercado, acompanhando a tendência atual do consumo de produtos in natura. Entretanto, as frutas minimamente processadas ainda são um desafio, devido à falta de conhecimento do comportamento fisiológico e bioquímico desses produtos. A vida curta útil desses produtos geralmente está ligada com as operações feitas no processamento (CAVALINI, 2008).

A utilização da embalagem pode diminuir a perda de massa fresca, as mudanças na aparência durante o tempo de armazenamento (KOSHI, 1988), com isso aumentar a vida de prateleira dos frutos, reduzir as perdas econômicas e facilitar a distribuição dos produtos sem comprometer a qualidade (FARBER, 1991).

O objetivo do trabalho foi estudar frutos de goiabeira da cultivar Sassaoka, submetida ao processamento mínimo e armazenada em dois tipos de embalagens, por oito dias.

\section{MATERIAL E MÉTODOS}

O experimento foi desenvolvido no Laboratório de Tecnologia de Alimentos, da Universidade Estadual Paulista "Júlio de Mesquita Filho" (Unesp), Câmpus de Ilha Solteira-- SP, com frutas produzidas na Fazenda de Ensino, Pesquisa e Extensão.

No laboratório, os frutos de goiabeira cv. Sassaoka foram lavados e desinfectados com hipoclorito de sódio (104 mg 100-1 L) por cinco minutos. Em seguida, descascados e cortados em fatias de aproximadamente um centímetro, as quais foram novamente desinfectadas com hipoclorito de sódio $\left(2 \mathrm{mg} 100^{-1} \mathrm{~L}\right)$ durante dois minutos e, em seguida, escorridas. As fatias foram acondicionadas nas embalagens em porções de aproximadamente 200 gramas. Os tratamentos foram: embalagem PET e em bandeja de isopor com filme plástico (espessura de $14 \mu \mathrm{m}$ ), em cinco tempos de armazenamento ( $0 ; 2 ; 4$ e 6 dias). As goiabas minimamente processadas ficaram armazenadas durante seis dias sob temperatura controlada de $8^{\circ} \mathrm{C}$, em BOD, e umidade de $80 \%$. A cada dois dias de armazenamento refrigerado foram retiradas três amostras de cada tratamento e analisadas com relação à perda de massa fresca (PMF), ao teor de sólidos solúveis ( $\mathrm{SS}$ ), acidez titulável (AT), vitamina $\mathrm{C}, \mathrm{pH}$ e análise visual.

A análise visual foi determinada pelo pesquisador, por meio de notas de 1 a 5, em que: 1- Péssimo: apresentando fungos (podridão); 2- Ruim: escurecido e sem fungos; 3- Regular: sem brilho e sem fungos (ainda comercialmente aceito); 4- Bom: cor opaca e sem fungos; 5- Ótimo: firme, cor normal e sem fungos.

O delineamento experimental utilizado foi o inteiramente casualizado (DIC), em esquema fatorial $2 \times 4$ (embalagem x épocas). As médias foram comparadas por meio do teste de Tukey, a $5 \%$ de probabilidade. Para as análises nos tempos de armazenamento, foi realizada regressão.

\section{RESULTADOS E DISCUSSÃO}

Na Tabela 1, observa-se que as goiabas armazenadas na embalagem PET obtiveram a menor perda de massa fresca, diferindo estatisticamente daquelas armazenadas em bandeja com filme plástico. Para $\mathrm{o} \mathrm{pH}$ e a acidez titulável, as frutas armazenadas em embalagem PET apresentaram-se mais ácidas em relação àquelas armazenadas em bandeja de isopor com filme plástico. Para os sólidos solúveis, observaram-se maiores valores para as goiabas armazenadas na bandeja de isopor com filme plástico, enquanto os teores de vitamina $\mathrm{C}$ foram maiores nas goiabas da embalagem PET. Para a aparência visual, os tratamentos não apresentaram diferença significativa entre si.

A menor perda de água na embalagem PET $(1,2725 \%)$ pode ser explicada pelo fato de essa embalagem não permitir a perda de água em excesso para o meio externo, sendo retida dentro da embalagem, fato comprovado pela maior condensação de água dentro da embalagem. O mesmo ocorreu com Lima et al. (2010) que, trabalhando com goiabas cv. Paluma minimamente processadas e armazenadas a $3 \pm 1^{\circ} \mathrm{C}$, observaram que as embalagens PET não foram apropriadas como era esperado, sendo que o acúmulo de condensação de água foi observado na superfície interna da tampa da embalagem, começando no segundo dia de armazenamento, comprometendo assim o aspecto geral do produto. Já nos frutos armazenados na bandeja com isopor, essa perda (2,915\%), provavelmente, esteja relacionada com as taxas de transpiração. Mattiuz (2002), ao armazenar goiabas minimamente processadas e acondicionadas em embalagem PET a $3^{\circ} \mathrm{C}$, obteve uma vida útil de nove dias, sendo a perda de matéria fresca de 3,06\%. A embalagem PET apresentou um $\mathrm{pH}$ mais ácido $(4,01)$ em relação à bandeja de isopor com filme plástico $(4,13)$ (Tabela 2$)$. Este comportamento, possivelmente, pode ter ocorrido devido à formação de ácidos orgânicos na embalagem PET, proveniente da degradação das paredes celulares, em relação à embalagem de isopor com filme plástico. 
O mesmo ocorreu para acidez titulável, em que as goiabas armazenadas na embalagem PET apresentaram uma AT superior $\left(0,364 \mathrm{~g}\right.$ ácido cítrico $100^{-1}$ gramas de polpa) à das goiabas acondicionadas na bandeja de isopor com filme plástico $(0,343 \mathrm{~g}$ ácido cítrico $100^{-1}$ gramas de polpa). Lima et al. (2010) observaram que as médias de AT em frutos de goiaba cv. Paluma minimamente processados e embalados em embalagem PET e embalagem PSPVC e armazenados por nove dias a $3 \pm 1^{\circ} \mathrm{C}$ mantiveram-se entre 0,63 e 1,10 mg de ácido cítrico $100^{-1}$ gramas de polpa, respectivamente, sem diferença estatística.

Os sólidos solúveis foram maiores nas goiabas acondicionadas na bandeja de isopor com filme plástico $\left(8,916^{\circ}\right.$ Brix $)$ quando comparadas às goiabas da embalagem PET $\left(8,716^{\circ} \mathrm{Brix}\right)$. Os teores de vitamina $\mathrm{C}$ foram maiores na embalagem PET (80,095 g de ácido ascórbico $100^{-1}$ gramas de polpa) em relação à bandeja de isopor com filme plástico (64,131 g de ácido ascórbico $100^{-1}$ gramas de polpa). Para a aparência visual, ocorreu declínio das notas atribuídas, sendo que as melhores notas foram dadas para a bandeja de isopor com filme plástico $(4,00)$, mostrando que as goiabas minimamente processadas e armazenadas nessa embalagem foram mais bem conservadas, mantendo melhor textura e aparência do produto, quando comparadas com a embalagem PET $(3,333)$. Essa maior conservação pode estar relacionada ao filme plástico e à bandeja de isopor, que pela mudança de atmosfera interna, e pode ter retardado o ciclo do etileno nos frutos de goiaba minimamente processados.

Pela Figura 1, verifica-se um efeito significativo para a porcentagem de perda de massa fresca em função do tempo de armazenamento. A reta apresentou comportamento linear crescente, alcançando uma perda superior a 3\%. Essa perda, com o avanço do período de armazenamento, pode ser atribuída à perda de umidade e de material de reserva pela transpiração e respiração, respectivamente. Chitarra e Chitarra (2005) citam que, de maneira geral, perdas da ordem de 3\% a 6\% são suficientes para acarretar um declínio na qualidade, causando o murchamento. $\mathrm{Na}$ interação das embalagens em função do tempo de armazenamento (Figura 1), nota-se diferença significativa das embalagens, com as retas com comportamento linear crescente, em que as maiores perdas foram verificadas na bandeja de isopor com filme plástico (superior a $4 \%$ ), provavelmente relacionadas com as taxas de transpiração e com perdas para o ambiente externo. A transpiração é o principal fator responsável pela perda de massa de produtos hortícolas durante o armazenamento, sendo reduzida pela barreira das embalagens pouco permeáveis ao vapor de água, criando um ambiente saturado no interior da embalagem e reduzindo o gradiente de pressão de vapor de água entre os tecidos internos das raízes e o interior da embalagem, evitando, assim, que os produtos se desidratem (CHITARRA; CHITARRA, 1990).

No $\mathrm{pH}$ (Figura 2), houve diferença estatística, e com o passar do período de armazenamento, apresentou tendência cúbica, partindo de $\mathrm{pH}$ 4,07 no momento do processamento, chegando aos dois dias a 4,12 (ponto de máxima), decaindo aos quatro dias para 4,01 e voltando a subir ao sexto dia para 4,08. Pereira et al (2003), trabalhando com goiabas Paluma minimamente processadas, não encontraram diferença significativa no $\mathrm{pH}$ em função do tempo de armazenamento.

Para as embalagens em função do tempo de armazenamento, a embalagem PET obteve tendência quadrática, partindo de 4,07 no momento do processamento, tendo um ponto de máxima no segundo dia com $\mathrm{pH}$ de 4,08 e decaindo até o sexto dia para 4,03. Essa diminuição do $\mathrm{pH}$ pode estar relacionada com a perda de água dos produtos minimamente processados, fazendo com que os ácidos fiquem mais concentrados. Scalon et al. (2004) observaram que sob refrigeração, os frutos de Eugenia uvalha Cambess apresentaram diminuição do $\mathrm{pH}$, o que foi demonstrado pela maior perda de água observada nessa condição, contribuindo assim, para a concentração dos ácidos orgânicos.

O teor de SS, em função do tempo (Figura 3), apresentou comportamento quadrático, com um valor máximo de $9,1^{\circ}$ Brix, e foi decaindo até o quarto dia, chegando a $7,61^{\circ}$ Brix, e posteriormente aumentando ao sexto dia até $9,03^{\circ}$ Brix. Os menores valores de SS observados no final do período de armazenamento indicaram que as fatias de goiaba mantiveram atividade metabólica mais intensa, tendo vida útil menor. Os resultados encontrados discordaram dos observados por Mattiuz et al. (2003), que verificaram manutenção do conteúdo de sólidos solúveis ao longo do armazenamento em goiabas 'Paluma' e 'Pedro Sato'. Lima et al. (2010) observaram que os teores de sólidos solúveis (SS) mantiveram valores num intervalo entre 8,80 e $10,53{ }^{\circ}$ Brix em goiabas cv. Paluma minimamente processadas, armazenadas por nove dias a $3^{\circ} \mathrm{C}$. Para as embalagens em função do tempo, a PET obteve comportamento linear ascendente, partindo de $9,1^{\circ}$ Brix e chegando ao sexto dia com $10,7^{\circ}$ Brix. Chitarra e Chitarra (2005) citam que o teor de açúcares atinge o valor máximo no final do amadurecimento, conferindo excelência de qualidade ao produto. Para a bandeja de isopor com filme plástico, a reta obteve comportamento linear 
decrescente, partindo de $9,1^{\circ}$ Brix no momento do processamento e chegando ao sexto dia com 7,36 ${ }^{\circ}$ Brix. Os teores de sólidos solúveis tenderam a cair com o decorrer dos dias. Provavelmente, essa queda dos teores está ligada com as injúrias feitas durante o processamento, que atua negativamente na qualidade do produto.

$\mathrm{O}$ teor de vitamina $\mathrm{C}$ foi influenciado pelo tempo de armazenamento (Figura 4). Houve um decréscimo nos dois primeiros dias de armazenamento, chegando a 59,9 mg de ácido ascórbico $100^{-1}$ gramas de polpa, e um acréscimo até o quarto dia com 70,6 $\mathrm{mg}$ de ácido ascórbico $100^{-1}$ gramas de polpa , e em seguida um decréscimo nos teores de vitamina $\mathrm{C}$ (53,3 mg de ácido ascórbico $100^{-1}$ gramas de polpa). A redução nos teores de vitamina $\mathrm{C}$, provavelmente, está associada com o etileno presente nos frutos climatéricos, o que concorda com Mattiuz et al. (2003), que verificaram diminuição no conteúdo de ácido ascórbico em goiabas 'Paluma'e 'Pedro Sato' minimamente processadas.

AAT, em função do tempo (Figura 5), mostra uma reta com comportamento quadrático, com 0,39 $\mathrm{g}$ de ácido cítrico $100^{-1}$ gramas de polpa no momento do processamento, decaindo para 0,338 gramas de ácido cítrico $100^{-1}$ gramas de polpa aos dois dias, voltando a subir no quarto dia para 0,36 gramas de ácido cítrico $100^{-1}$ gramas de polpa e decaindo para 0,326 $\mathrm{g}$ de ácido cítrico $100^{-1}$ gramas de polpa ao sexto dia. Essa leve diminuição pode estar ligada ao amadurecimento das goiabas, tendendo os ácidos orgânicos a diminuir nesse período. Discordando de Jacomino et al. (2002), estudando goiabas 'Kumagai' e Lima, e Durigan (2000) estudando goiabas 'Pedro Sato', que observaram um leve aumento no teor de AT, durante $\mathrm{o}$ armazenamento, em diferentes embalagens, sob refrigeração a $10^{\circ} \mathrm{C}$. Mattiuz (2002), avaliando o efeito de danos mecânicos em goiabas 'Pedro Sato' e 'Paluma', observou aumento dos teores de acidez até o quarto dia após a colheita. Para as embalagens em função do tempo de armazenamento, a embalagem PET obteve comportamento quadrático com ponto máximo no momento do processamento $(0,39$ g de ácido cítrico $100^{-1}$ gramas de polpa), chegando ao sexto dia com uma acidez titulável de $0,336 \mathrm{~g}$ de ácido cítrico $100^{-1}$ gramas de polpa. Apesar das oscilações dos teores, verifica-se redução na AT no final do processamento, em comparação com o início do (?) processamento. $\mathrm{Na}$ bandeja de isopor com filme plástico, observa-se uma tendência linear decrescente, partindo de $0,390 \mathrm{~g}$ de ácido cítrico $100^{-1}$ gramas de polpa e chegando a $0,316 \mathrm{~g}$ de ácido cítrico $100^{-1}$ gramas de polpa ao sexto dia. Segundo Chitarra e Chitarra (1990), os frutos, com o amadurecimento, perdem rapidamente a acidez, mas, em alguns casos, há um pequeno aumento nos teores com o avanço do amadurecimento.

Em relação à aparência visual, observa-se, na Figura 6, um declínio das notas atribuídas à aparência durante o armazenamento refrigerado, de 5 (ótimo) a 2,33 (ruim). As goiabas minimamente processadas tiveram boas condições para consumo até o quarto dia (nota 3 - regular) após processado, sendo que as goiabas minimamente processadas, com notas menores que 3 (regular), apresentaram escurecimento, podridões e aparecimento de fungos. Segundo Cantwell e Suslow (2002), as operações envolvidas na preparação de frutas e hortaliças minimamente processadas, geralmente, reduzem a vida de prateleira das mesmas, pois levam a mudanças fisiológicas que resultam em prejuízos à aparência.

Para as embalagens em função do tempo de armazenamento, ambas as retas obtiveram um comportamento linear decrescente, mostrando que, com o decorrer do tempo de armazenamento, as notas foram decaindo, partindo de nota 5 (ótimo) no momento do processamento e chegando ao sexto dia com nota 2 (ruim) para a embalagem PET e 2,66 (ruim) para a bandeja de isopor com filme plástico. $\mathrm{O}$ mesmo ocorreu com Arruda et al. (2004) que, trabalhando com melões Honeydew minimamente processados, armazenados a $3{ }^{\circ} \mathrm{C}$, verificaram um declínio na aparência quando diferentes tipos de embalagem foram testados (BB200 filme multicamada; filme poliolefínico e filme de polipropileno). 
TABELA 1 - Valores médios das características físicas e químicas de frutos de goiabeira cv. Sassaoka, minimamente processados e armazenados sob diferentes tratamentos. Ilha Solteira - SP. 2010.

\begin{tabular}{lllllll}
\hline TRATAMENTOS & PMF & pH & SS & AT & VIT C & AV \\
\cline { 2 - 7 } Embalagem PET & $1,272 \mathrm{a}$ & $4,01 \mathrm{a}$ & $8,716 \mathrm{a}$ & $0,364 \mathrm{a}$ & $80,095 \mathrm{a}$ & $3,333 \mathrm{a}$ \\
Bandejacom isopor & $2,915 \mathrm{~b}$ & $4,13 \mathrm{~b}$ & $8,916 \mathrm{~b}$ & $0,343 \mathrm{~b}$ & $64,131 \mathrm{~b}$ & $4,000 \mathrm{~b}$ \\
\hline C.V(\%) & 32,27 & 1,22 & 7,14 & 4,9 & 18,27 & 10,42 \\
\hline
\end{tabular}

Médias seguidas da mesma letra na linha não diferem entre si, pelo teste de Tukey, ao nível de 5\% de significância.

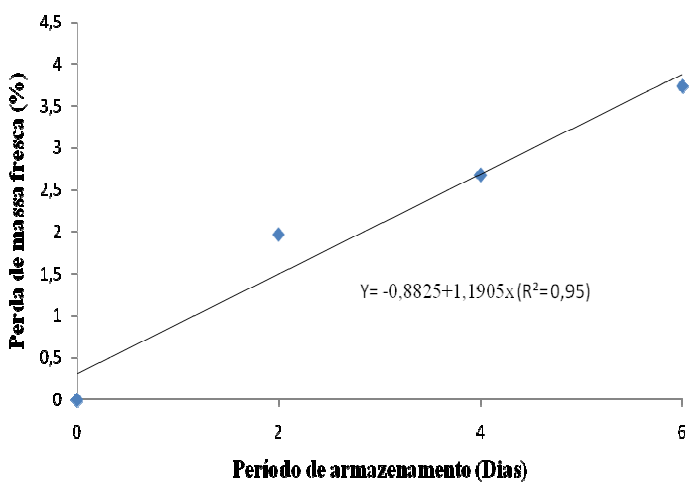

(A)

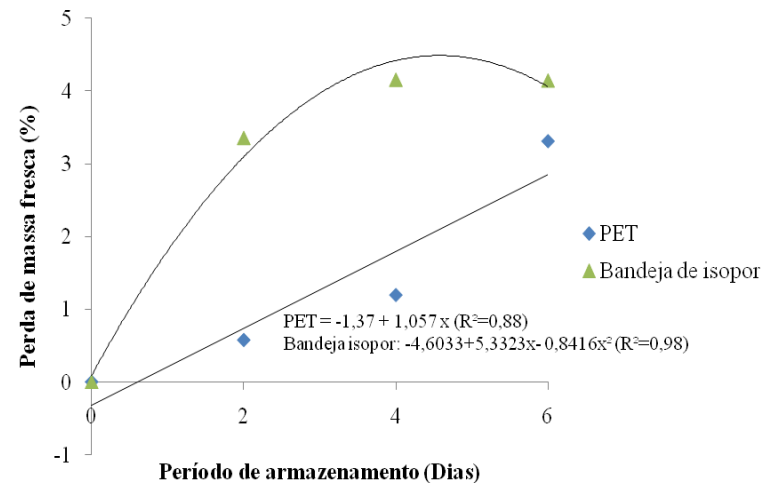

(B)

FIGURA 1 - Perda de massa fresca (\%) de frutos de goiabeira cv. Sassaoka, minimamente processados, em função do período de armazenamento (A) e das diferentes embalagens utilizadas (B). Ilha Solteira - SP, 2010.

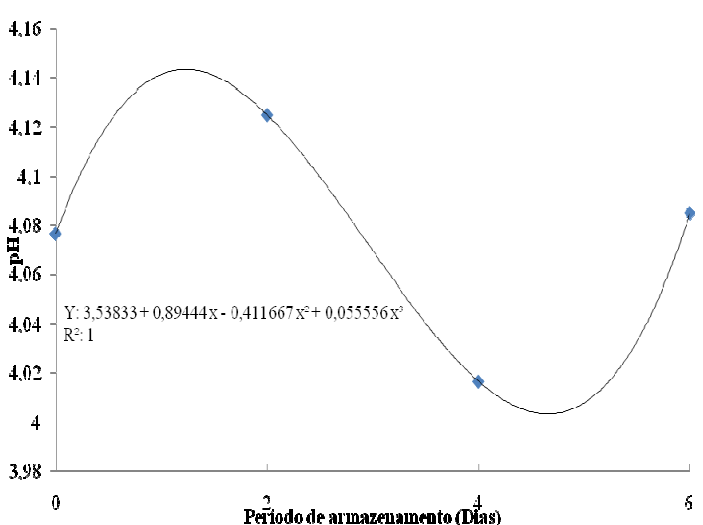

(A)

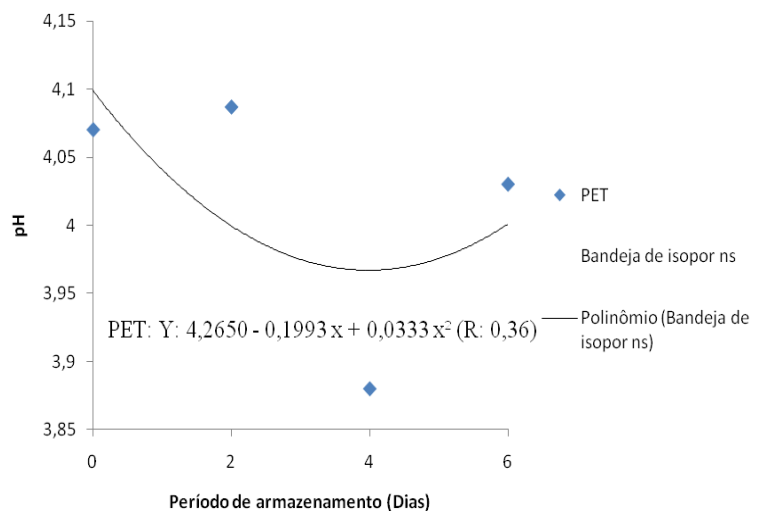

(B)

FIGURA 2 - p.H de frutos de goiabeira cv. Sassaoka, minimamente processados, em função do período de armazenamento (A) e das diferentes embalagens utilizadas (B). Ilha Solteira - SP, 2010. 


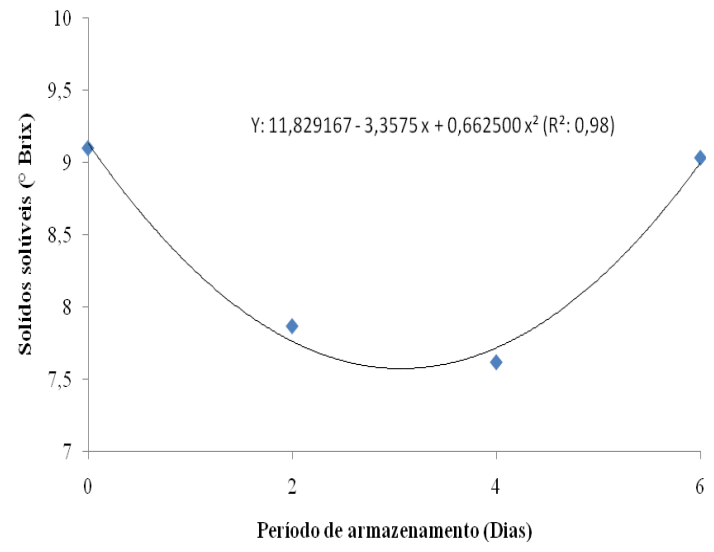

(A)

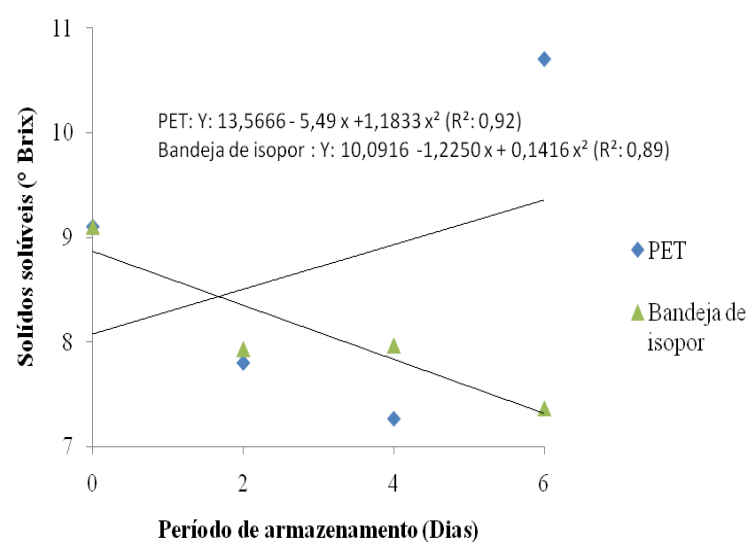

(B)

FIGURA 3 - Sólidos solúveis $\left({ }^{\circ}\right.$ Brix) de frutos de goiabeira cv. Sassaoka, minimamente processados, em função do período de armazenamento (A) e das diferentes embalagens utilizadas (B). Ilha Solteira - SP, 2010.

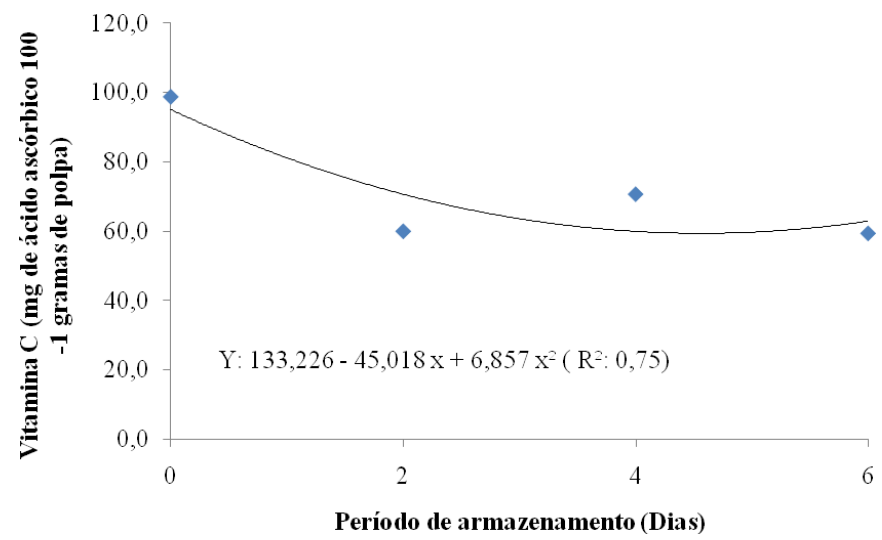

FIGURA 4 - Teores de vitamina $\mathrm{C}$ de frutos de goiabeira cv. Sassaoka, minimamente processados, em função do período de armazenamento. Ilha Solteira - SP, 2010.

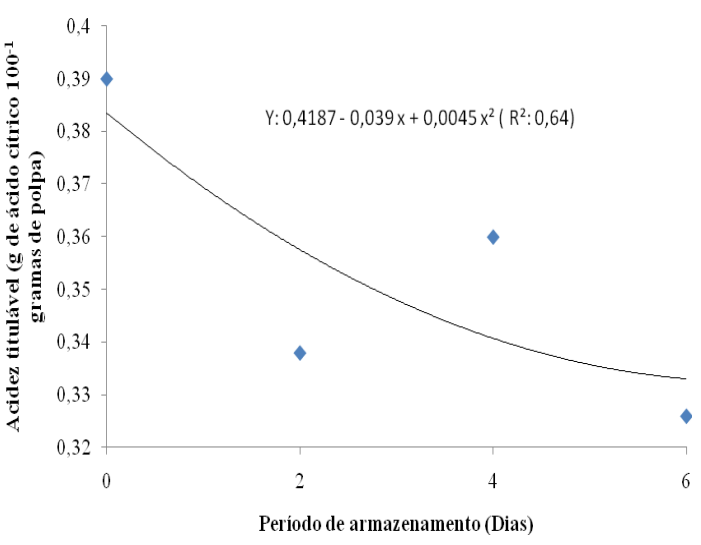

(A)

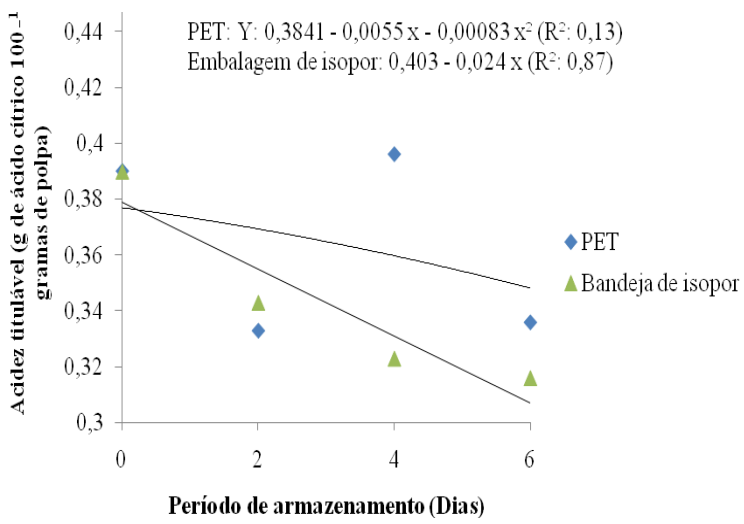

(B)

FIGURA 5 - Acidez titulável de frutos de goiabeira cv. Sassaoka, minimamente processados, em função do período de armazenamento (A) e das embalagens (B) . Ilha Solteira - SP, 2010. 


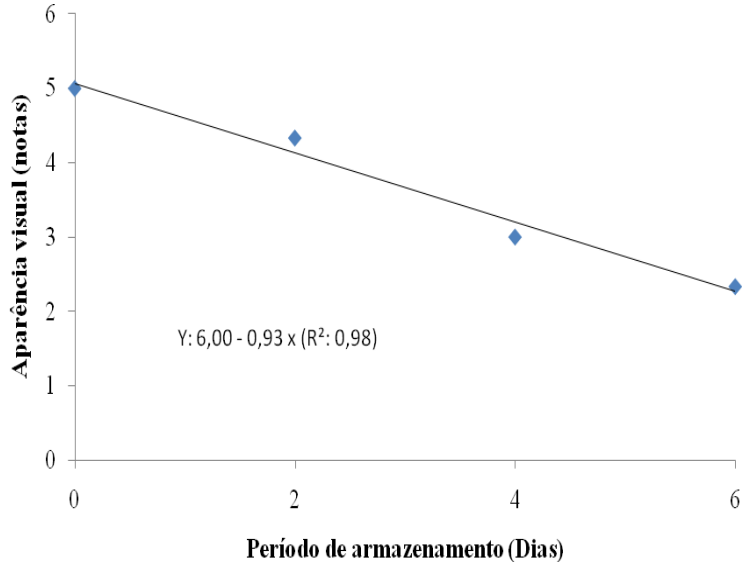

(A)

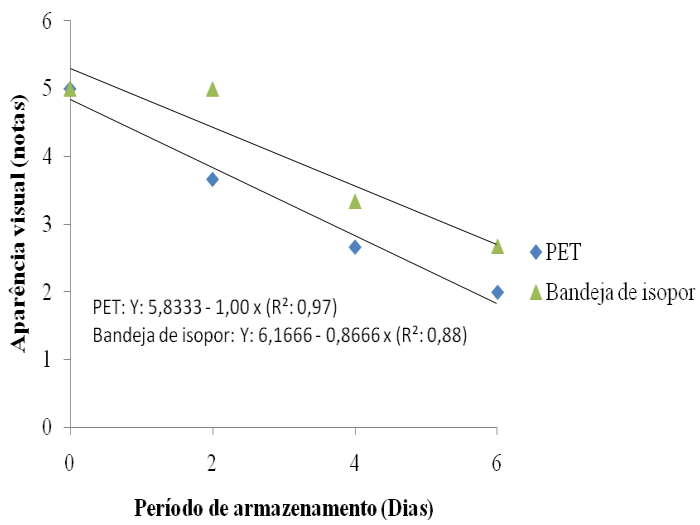

(B)

FIGURA 6 - Aparência visual de frutos de goiabeira cv. Sassaoka, minimamente processados, em função do período de armazenamento (A) e das diferentes embalagens utilizadas (B). Ilha Solteira - SP, 2010.

\section{CONCLUSÃO}

A embalagem de isopor (bandeja) com filme plástico proporcionou melhor conservação para as goiabas minimamente processadas, quando comparada com a embalagem PET, mantendo os frutos em boas condições por até quatro dias após processados.

\section{AGRADECIMENTO}

À FAPESP, pelo apoio concedido.

\section{REFERÊNCIAS}

ARRUDA, M. C. et al. Conservação de melão rendilhado minimamente processado sob atmosfera modificada ativa. Ciência e Tecnologia de Alimentos, Campinas, v.24, n.1, p.53-58, 2004.

CANTWELL, M. I.; SUSLOW, T. V. Postharvest handling systems: fresh cut fruits and vegetables. In: KADER, A.A. (Ed.). Postharvest technology of horticultural crops. $3^{\text {rd }}$ ed. Davis: University of California, 2002. p.445-463.

CAVALINI, F. C. Fisiologia do amadurecimento, senescência e comportamento respiratório de goiabas 'Kumagai' e 'Pedro Sato'. 2008. 90f. Tese (Doutorado em Fisiologia e Bioquímica de Plantas) - Escola Superior de Agricultura 'Luiz de Queiroz', Universidade de São Paulo, Piracicaba, 2008.
Chitarra, M. I. F.; Chitarra, A. B. Póscolheita de frutas e hortaliças: fisiologia e manuseio. Lavras: UFLA, 2005. 783p.

Chitarra, M. I. F.; ChitarRa, A. B. Póscolheita de frutos e hortaliças: fisiologia e manuseio. Lavras: ESAL/FAEPE. 1990. 320 p.

FARBER, J. M. Microbiological aspects of modified atmosphere packing technology- a review. Journal of Food Protection, Ames, v.54, n.1, p.58-70, 1991.

INSTITUTO ADOLFO LUTZ. Normas analíticas do Instituto Adolfo Lutz: I métodos químicos e físicos para análise de alimentos. 3.ed. São Paulo, 1985. 533p.

JACOMINO, A. P. et al. Amadurecimento e senescência de mamão com 1-metilciclopropeno. Scientia Agricola, Piracicaba, v.59, n.1, p.303-308, 2002.

KOSHI, D.V. Is current modified / controlled atmosphere packaging technology applicate to U.S. food market. Food Technology, Chicago, v.28, n 9, p.50-60, 1988 .

LIMA, M. S. et al. Quality of minimally processed guava with different types of cut, sanification and packing. Ciência e Tecnologia de Alimentos. Campinas, v.30, n.1, p.79-87, 2010. 
LIMA, M. A.; DURIGAN, J. F. Conservação de goiabas 'Pedro Sato' associando-se refrigeração com diferentes embalagens. Revista Brasileira de Fruticultura, Jaboticabal, v.22, n.1, p.232-236, 2000.

MATTHEIS, J. P.; FELLMAN, J. K. Preharvest factors influencing flavor of fresh fruit and vegetables. Postharvest Biology and Technology, Amsterdam, v.15, n.1, p.227-232, 1999.

MATTIUZ, B. H.; DURIGAN, J. F.; ROSSI JÚNIOR, O. D. Processamento mínimo em goiabas "Paluma e "Pedro Sato": avaliação química, sensorial e microbiológica. Ciência e Tecnologia de Alimentos, Campinas, v.23, n.3, p.409-413, 2003.
MATTIUZ, B. Fisiologia e qualidade pós-colheita de goiabas. 2002. 118f. Tese (Doutorado em Produção Vegetal)- Faculdade de Ciências Agrárias e Veterinárias, Universidade Estadual Paulista, Jaboticabal, 2002.

PEREIRA, L. M. et al. Vida de prateleira de goiabas minimamente processadas acondicionadas em embalagens sob atmosfera modificada. Ciência Tecnologia de Alimentos, Campinas, v.23, n.3, p.427-433, 2003.

SCALON, S. P. Q.; DELL'OLIO, P.; FORNASIERI, J. L. Temperatura e embalagens na conservação pós-colheita de Eugenia uvalha Cambess - Mirtaceae. Ciência Rural, Santa Maria, v.34, n.6, p.1965-1968, 2004. 